\title{
Reflecting on BCMP students' experiences of professionalism during clinical rotations
}

\author{
Nontsikelelo Mapukata-Sondzaba, ${ }^{1}$ MSc, BTech; Ames Dhai, ${ }^{2}$ MB ChB, FCOG (SA), LLM \\ 'Division of Rural Health, Faculty of Health Sciences, University of the Witwatersrand, Johannesburg, South Africa \\ ${ }^{2}$ Steve Biko Centre for Bioethics, Faculty of Health Sciences, University of the Witwatersrand, Johannesburg, South Africa
}

Corresponding author: Nontsikelelo Mapukata-Sondzaba(Nontsikelelo.Sondzaba@wits.ac.za)

\begin{abstract}
Background: The professional standards expected of individuals who commit to the practice of medicine require that they possess character traits that are consistent with and reflect the core values, principles and competencies of the medical profession.

Objective: The aim was to evaluate final year Bachelor of Clinical Medical Practice (BCMP) students' experiences of professionalism during clinical rotations.

Method: Hatem's definition of professionalism was the stimulus that guided 25 final year BCMP students' reflections on their experiences of professionalism during clinical rotations. The students' responses documented as portfolio entries were distilled into quantitative core values and subjected to an ethical analysis according to the guidelines as provided by the Health Professions Council of South Africa.

Results: There was a positive association between frequency of reflections and the positive nature of the experiences of professionalism for the majority of the contextual attributes (53.8\%). Negative experiences of professionalism $(46.2 \%)$ were context-specific and perceived by students as denying them an opportunity to attain professionally required skills.

Conclusion: BCMP students reflected on their professional development as a process that was influenced by individuals and a competency that was determined by the extent to which the team pulled together for the benefit of the patients and the students. The study has highlighted some of the ethical dilemmas related to context.
\end{abstract}

SAfr J BL 2015;8(1):26-29. DOI:10.7196/SAJBL.372

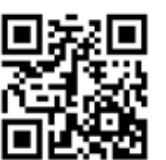

This article is a second article emanating from a larger study titled: Reflecting on professionalism: An analysis of Bachelor of Clinical Medical Practice (BCMP) students' portfolios during clinical rotations. An article is already published as open access by BMC: Medical Education. ${ }^{[1]}$ The aim of this article is to report on the experiences of professionalism as reflected on by final year BCMP students' during clinical rotations.

The professional standards expected of individuals who commit to the practice of medicine require that they possess character traits that are consistent with and reflect the core values, principles and competencies of the medical profession. ${ }^{[2]}$ As medicine is no longer considered only as a profession par excellence, the humanistic element is critical in the development of a professional identity. ${ }^{[3]}$ Health sciences students are not yet professionals, but rather are professionals in training, and should be trained in the same environment in which they will practise. ${ }^{[4]} \mathrm{As}$ today's healthcare provision is patientcentred, the requirement to maintain professional standards must be facilitated and modelled in the training environment to simulate a real setting, maintained and sustained in all heathcare facilities for the good of the patient. ${ }^{[5]}$ This exposure allows students to meet the expectations of their patients and also be afforded an opportunity to simulate professional behaviour that is modelled on the conduct of their supervisors in the clinical setting. ${ }^{[6,7]}$

This understanding of the attainment of professionalism not as an event but rather as a process obligates both the academic and the clinical environment to engage students in the attainment of a sound and professional ethic that will benefit patients and society. ${ }^{[5]}$ Further to this, universities are required to meet the standards of professional education and training as prescribed by the Health Professions Council of South Africa (HPCSA) and prepare students for professional practice. ${ }^{[8]}$ This was true for the BCMP programme which accepted its first cohort of students at the University of the Witwatersrand (Wits) in January 2009. ${ }^{[1]}$ With a unique and integrated curriculum, the students are based in District Education Campuses in urban and/or underserved facilities in Gauteng or in rural facilities in the North West Province. On completion of their studies, these healthcare practitioners are known as Clinical Associates and are based in district hospitals where they work under the supervision of a family physician. ${ }^{[1]}$ Contextual attributes of professionalism - also referred to as core elements by the HPCSA - are attributes or domains that constitute a spectrum of behaviours that should be exhibited by all categories of healthcare practitioners (HCPs) at the end of the training period. ${ }^{[10]}$ They are the desired qualities in any doctor-patient relationship that need to be displayed in the contexts in which they practise and are associated with the physician as a healer in society. ${ }^{[5,6]}$ In this study, the contextual attributes were assessed in terms of the thirteen core values of professionalism as described by the HPCSA, namely: respect for persons; beneficence; non-maleficence; human rights; autonomy; integrity; truthfulness; confidentiality; compassion; tolerance; justice; professional competence and selfimprovement, and community. ${ }^{[10]}$

\section{Methods}

Hatem's ${ }^{[9]}$ definition of professionalism (Box 1) adopted as a working definition for the BCMP programme was the stimulus that 
guided the 25 final year BCMP students' reflections. The students' experiences of the contextual attributes of professionalism during clinical rotations were received as portfolio entries. As research instruments, the benefits of employing portfolios are well documented. ${ }^{[11]}$

In total, 71 portfolios reflecting the experiences of BCMP students in individual departments in facilities designated as District Education Campuses were analysed as follows: $100 \%$ $(n=25)$ in Emergency Medicine (EM), $92 \%(n=23)$ each for adult in-patient wards (AIPW) and Paediatrics (Paeds). For a detailed description on the research design - a retrospective, descriptive, analytical case - based study as well as data collection methods, the reader is directed to the published article. ${ }^{[1]}$ Ethical clearance was obtained from the Human Research Ethics Committee (HREC Medical: M110740) of the Faculty of Health Sciences at Wits. BCMP students' responses informed by Hatem's definition, were openended and not grouped into categories. However, for the purpose of the analysis, the core values were distilled according to the HPCSA guidelines that direct the practice of healthcare professionals in South Africa. ${ }^{[10]}$ The identified contextual attributes were analysed by grouping the students' experiences in Paeds, $E M$ and AIPW into sub-themes. The findings were then computed using simple descriptive statistical methods captured on an Excel spreadsheet. ${ }^{[11]}$ Presented as percentage values they demonstrated frequency distribution and the relationship of grouped data that was then subjected to an ethical analysis.

\section{Results}

The BCMP students reported on all the attributes of professionalism described as the core values by the HPCSA (Table 1). There was a positive association between frequency of reflections and the positive nature of the experiences of professionalism for the majority (53.8\%) of the attributes including: respect for persons, beneficence, integrity, truthfulness, compassion, tolerance, and professional competence and self-improvement. For some of the attributes, at $23.1 \%$, (confidentiality, autonomy, community) students had a range of experiences leading to on-going debate and internal conflict as they had to navigate parents or family interests, as well as traditional and cultural practices. For the remaining attributes (non-maleficence, justice and human rights), also at $23.1 \%$, the reflections were guided by negative experiences.

\section{Discussion Respect}

Many of the BCMP students' experiences of respect shown to patients were in the Paeds department, similar to a study commissioned by a university in the USA.
Table 1: Contextual attributes of professionalism $(n=25)$

\begin{tabular}{|c|c|c|c|c|c|c|}
\hline \multirow[t]{2}{*}{ Core Elements } & \multicolumn{2}{|c|}{ Paediatrics (PAEDS) } & \multicolumn{2}{|c|}{$\begin{array}{l}\text { Adult in-Patients } \\
\text { Ward (AIPW) }\end{array}$} & \multicolumn{2}{|c|}{$\begin{array}{c}\text { Emergency Medicine } \\
\text { (EM) }\end{array}$} \\
\hline & $n=23$ & $\%$ & $n=23$ & $\%$ & $n=25$ & $\%$ \\
\hline Respect & 18 & 78.2 & 12 & 52.2 & 10 & 40.0 \\
\hline Beneficence & 9 & 39.1 & 5 & 21.7 & 2 & 8.0 \\
\hline Non-maleficence & 6 & 26.1 & 3 & 13.0 & 2 & 8.0 \\
\hline Human rights & 5 & 21.7 & 6 & 26.1 & 8 & 32.0 \\
\hline Autonomy & 11 & 47.8 & 6 & 26.1 & 8 & 32.0 \\
\hline Integrity & 14 & 60.9 & 12 & 52.2 & 7 & 28.0 \\
\hline Truthfulness & 9 & 39.1 & 9 & 39.1 & 7 & 28.0 \\
\hline Confidentiality & 8 & 34.7 & 14 & 60.9 & 10 & 40.0 \\
\hline Compassion & 14 & 60.9 & 6 & 26.1 & 8 & 32.0 \\
\hline Tolerance & 13 & 56.5 & 7 & 30.4 & 5 & 20.0 \\
\hline Justice & 8 & 34.8 & 7 & 30.4 & 10 & 40.0 \\
\hline $\begin{array}{l}\text { Professional } \\
\text { competence /self- } \\
\text { improvement }\end{array}$ & 18 & 78.2 & 14 & 60.9 & 30 & 120.0 \\
\hline Community & 9 & 39.1 & 9 & 39.1 & 6 & 24.0 \\
\hline
\end{tabular}

One of the students reflected on respect that was extended to a third party - a parent to one of the patients. The only difference was that the findings of the US study were based on a narrative undertaken by medical students doing an EM clerkship. ${ }^{[12]}$

\section{Beneficence}

The BCMP students reflected on the same issues reported by Bernard ${ }^{[11]}$ when they considered the limits of their practice, the need for ongoing learning and being the best you can be for your patients. In AIPW it was the plight of admitted patients to which students were sensitised.

\section{Non-maleficence, justice and human rights violation}

In this study BCMP students observed patients being hurt by a HCP as one of the students made reference to instances where a HCP refused to attend to a homeless person. In this regard, BCMP students observed discrimination towards patients at three levels. In the first instance they observed different standards of care for different patients depending on who they were and their social standing in society. Secondly, they referred to the treatment meted out to patients who were classified as non-South Africans when they failed to present an identity document on admission. The third violation was cited as instances where patients were compromised by their presenting illness. One student referred to an incident in theatre where the attending doctor made fun of a patient who presented with an inguinal hernia. Similar findings are reported in studies conducted in other universities. ${ }^{[14-17]}$

\section{Autonomy}

BCMP students engaged with the complexity of the consent process and subsequent challenges in obtaining informed consent. ${ }^{[15,18]}$ Students referred to the 'dynamics of the consent process that are unique to South Africa' as they

"The extended set of responsibilities that include the respectful, sensitive focus on individual patient needs that transcends the physician's self-interest, the understanding and use of the cultural dimension in clinical care, the support of colleagues, and the sustained commitment to the broader societal goals of medicine as a profession".

Box 1. Hatem's definition of professionalism 
linked the health-seeking behaviour of the parents in Paeds with their traditional belief system. The experiences of the students are supported by Tsotsi ${ }^{[19,20]}$ who refers to the process of attaining informed consent in developing countries as a complex issue or a contentious issue that is context-specific. ${ }^{[2]]}$

\section{Truth-telling}

BCMP students observed that for many of the adolescents, poor communication between HCPs and the patients was contrary to the best interests of the patients. The dilemma around the issue of trust that students faced was based on the fact that there was no consensus, e.g. when was the right time to tell a child that he was HIV-infected or the reason why his parents died? With the majority of patients expecting to be told the truth about their condition ${ }^{[21]}$ the students felt it was unfair for patients to be expected to take chronic medication for life if they did not understand the associated value. While truth-telling is not always encouraged for various reasons, e.g. emotional status of the patient, withholding or giving false information to patients and/or families is considered to be unethical conduct. ${ }^{[22]}$

\section{Confidentiality}

The privacy of patient information was seen as a contentious issue that led to many violations of confidentiality due to systemic issues. It presented a challenge especially in AIPW as a result of the economic setup of the wards. BCMP students reflected on instances where the family demanded to know intimate details about their relative, thereby creating a dilemma for the HCP who could not disclose information without violating the rights of the admitted adult patient. This entitlement to patient information is often associated with particular settings as similar findings were reported in Uganda and elsewhere in Africa. ${ }^{[2]}$

\section{Compassion and care}

BCMP students reflected on the value of demonstrating compassion and care in the clinical setting as an attribute mainly observed in Paeds similar to findings reported in two studies conducted in the USA. ${ }^{[11,12]}$ The positive reflections that BCMP students experienced in Paeds were consistent with and met the recommendations of the HPCSA that require HCPs to always show regard for their patients as their primary professional duty. ${ }^{[10]}$

\section{Tolerance}

The expectation for HCPs to be culturally competent is considered a moral requirement that informs the professional conduct of HCPs. Students were conscientised to the clinician's dilemma and the required tolerance in negotiating with parents when they demanded that critically ill children be discharged or with relatives who refused to accept healthcare such as therapeutic amputation of a limb, if it was not culturally or religiously acceptable. ${ }^{[20]}$ In teaching professionalism, due consideration should be given to respect for local customs and related to the different cultures within that context. ${ }^{[24]}$

\section{Community experience}

Many of the BCMP students' reflections on their community experience that informed and motivated students to contribute to the betterment of society were born out of frustration. Students reflected not only on their experiences but also on what they felt should be taken into account to improve the plight of the community regarding the number of patients who refused hospital treatment (RHT) in Paeds and in AIPW and to a lesser degree in EM. ${ }^{[23]}$ Traditional practice in rural communities was the most likely reason underpinning the request for RHT. While patients have a right to refuse treatment, the decision must be rational and fully informed. ${ }^{[18]}$ Concerns expressed by the BCMP students with regard to observed RHT practice are supported by $\mathrm{Crain}^{[25]}$ as he considered morality and rights-based healthcare to be informed by the propensity of the healthcare community to preserve the value of life.

\section{Professional integrity}

As an observed attribute for many of the admitted patients as reflected in portfolios in Paeds and in AIPW but not so much in EM, BCMP students witnessed a virtue that requires both moral and intellectual excellence and a measure that limits violations to the profession. ${ }^{[26]}$

\section{Professional development}

BCMP students reflected on their professional development as a process acquired either through observed role modelling or their experiences of being mentored, as students enjoyed exceptional positive experiences in EM but also in Paeds and in AIPW. ${ }^{[7]}$ Teamwork was a critical area of development that was noted by students as contributing to their learning and improvement of skills. Students were of the view that their own competence was determined by the extent to which the team cooperated and pulled together for the benefit of the patient and the student as a trainee HCP. ${ }^{[12]}$ Appraising medical students' reflection-inlearning, Sobral ${ }^{[13]}$ makes reference to a positive correlation between quality of reflections and a readiness to self-regulate as well as perceived learning autonomy. The present data support the assertion by Swick ${ }^{[6]}$ when the value of professionalism is considered from two levels namely the individual and the collective. Students were motivated to do more when they were in teams. In instances where the experience was negative, students perceived this as denying them an opportunity to attain desired and professionally required skills. ${ }^{[16]}$

\section{Limitations}

It should be noted that the data in this study were not primarily intended for research purposes. ${ }^{[1]}$ Nonetheless rich data sets, obtained using acceptable scientific methods, had to be compressed to answer critical questions for this programme.

\section{Conclusion}

Hatem's definition of professionalism as a stimulus for this research facilitated for context-specific learning and experiences of role modelling especially in Paeds. Overall, the findings in this study support student exposure to community issues as one of the valuable approaches to learning about professionalism. The BCMP students had to consider the cultural dimensions in clinical care as they interacted with patients in their context. The value of learning about professionalism was considered at two levels where the BCMP students considered not only their role as individuals but also the extent to which their competencies were influenced by a team approach. The study has highlighted some of the ethical dilemmas related to context that need to be considered when students are based in local communities. 
Competing interests. The authors declare that they have no competing interests.

Funding. This study was self-funded.

Authors' contributions. Nontsikelelo Mapukata-Sondzaba conceptualised the research and drafted the article. Ames Dhai provided critical review during the writing phase, read and approved the final manuscript.

Acknowledgements. Gratitude is extended to the BCMP class of 2011, to Professor Ross and Dr Norma Tsotsi who provided valuable advice during the research process.

\section{References}

1. Mapukata-Sondzaba N, Dhai A, Tsotsi N, Ross E. Developing personal attributes of professionalism during clinical rotations: Views of final year bachelor of clinical medical practice students. BMC Med Educ 2014;14:146 [http://dx.doi. org/10.1186/1472-6920-14-146]

2. Dhai A, McQuoid-Mason D. Editorial: What does professionalism in healthcare mean in the 21st Century? S Afr J BL 2008;1(1):2-3.

3. Mueller PS. Incorporating professionalism into medical education: The Mayo Clinic experience. Keio J Med 2009;58(3):133-143. [http://dx.doi.org/10.2302/kjm.58.133]

4. Asghari F, Fard, NN, Atabaki A. Are we proper role models for students? Interns' perception of faculty and residents' professional behaviour. Postgrad Med J 2011;87(1030):519-523 [http://dx.doi.org/ doi: 10.1136/pgmj.2010.110361]

5. Cruess SR. Professionalism and medicine's social contract with society. Clin Orthop Relat Res 2006:449:170-176.

6. Swick HM. Toward a normative definition of medical professionalism. Acad Med 2000;75(6):612-616.

7. Harris GD. Professionalism: Part I - Introduction and being a role model. Fam Med 2004;36(5):314-315

8. Health Professions Council of South Africa. Core curriculum on human rights, ethics and medical law for health care professionals. Pretoria: HPCSA. 2006.

9. Hatem CJ. Teaching approaches that reflect and promote professionalism. Acad Med 2003:78(7):709-713.

10. Health Professions Council of South Africa. Guidelines for Good Practice in the Health Care Professions. General ethical guidelines for health care professions. Booklet 1. 2008. http://www.hpcsa.co.za/hpcsa/default.aspx (accessed 8 May 2008).

11. Bernard AW, Malone M, Kman NE, Caterino JM, Khandelwal S. Medical Student Professionalism Narratives: A Thematic Analysis and Interdisciplinary Comparative Investigation. BMC Emerg Med 2011;11:121 [http://dx.doi. org/10.1186/1471-227X-11-11]]
12. Curry $\mathrm{SE}$, Cortland $\mathrm{Cl}$, Graham MJ. Role-modelling in the operating room: Medical student observations of exemplary behaviour. Med Educ 2011:45(9):946-957 [http://dx.doi.org/doi: 10.1111/j.1365-2923.2011.04014.x.]

13. Sobral DT. An appraisal of medical students'reflection-in-learning. Med Educ 2000;34(3):182-187.

14. Szauter K, Williams B, Ainsworth MA, Callaway M, Bulik R, Camp MG. Student perception of the professional behaviour of family physicians. Med Educ 2003:8:17.

15. Kaldjian LC, Rosenbaum ME, Shinkunas LA, Woodhead JC, Antes LM, Rowat JA, Forman-Hoffman VL. Through students' eyes: Ethical and professional issues identified by third-year medical students during clerkships. J Med Ethics 2012;38(2): 130-132 [http://dx.doi.org/doi: 10.1136/ medethics-2011-10003310.1136/medethics-2011-100033]

16. Feudtner D, Christakis DA, Christakis N.A. Do clinical clerks suffer ethical erosion? Students' perceptions of their ethical environment and personal development Acad Med 1994;69(8):670-79.

17. Vivian LMH, Naidu CS, Keikelame MJ, Irlam J. Medical students' experiences of professional lapses and patient rights abuses in a South African health sciences faculty. Acad Med 2011;86(10):1282-1287 [http://dx.doi.org/10.1097/ ACM.0b013e31822be4b8

18. Health Professions Council of South Africa. Seeking Patients' Informed Consent: The Ethical Considerations, 2 ${ }^{\text {nd }}$ Edition. Booklet 10. 2007. http://www.hpcsa. co.za/hpcsa/default.aspx (accessed 8 May 2008).

19. Tsotsi N. Informed Consent In Research In Developing Countries: Is There Some Unfinished Business? Dissertation submitted in partial fulfilment of the requirement of the degree Master of Science in Medicine (Bioethics and Health Law). Faculty of Health Sciences. University of the Witwatersrand; 2009.

20. Baingana K, Nakasujja N, Galukande M, Omona K, Mafigiri DK, Sewankambo NK Learning health professionalism at Makerere University: An exploratory study amongst undergraduate students. BMC Med Educ 2010;10:76. [http://dx.doi. org/10.1186/1472-6920-10-76]

21. Vangu MDTW. Truth telling in a South African tertiary hospital. S Afr J BL 2010;3(1):38.

22. Kovatz S, Shenkman L. Unethical behaviour witnessed by medical students during their medical studies. The Open Ethics Journal 2008;2:26-28.

23. O'Sullivan M, Martin J, Murray E. Students' perceptions of the relative advantages and disadvantages of community-based and hospital-based teaching: A qualitative study. Med Educ 2000;34(8):648-655. [http://dx.doi.org/10.1046/ j.1365-2923.2000.00623.x]

24. Cruess SR, Cruess RL, Steinert Y. Linking the teaching of professionalism to the social contract: A call for cultural humility. Med Teach 2010;32(5):357-359 [http:// dx.doi.org/10.3109/01421591003692722]

25. Crain WC. Kohlberg's stages of moral development. Theories of Development. New Jersey: Prentice-Hall,1985:118-136.

26. Chervenak FA, McCullogh LB. Professional integrity, respect for autonomy, and the self-regulation of reproductive endocrinology. Am J Obstet Gynecol 2009;201(1)3-4 [http://dx.doi.org/10.1016/j.ajog.2009.05.029] 